\title{
(2) OPEN ACCESS \\ Patient-reported outcome score utilisation in arthroscopic hip preservation: we are all doing it differently, if at all
}

\author{
Derek M Klavas, ${ }^{1}$ Neil Duplantier, ${ }^{1}$ Brayden Gerrie, ${ }^{1}$ Patrick C McCulloch, ${ }^{1}$ \\ Shane J Nho, ${ }^{2}$ Kevin E Varner, ${ }^{1}$ Joshua D Harris (i) ${ }^{1}$
}

\begin{abstract}
- Additional material is published online only. To view please visit the journal online (http://dx.doi.org/10.1136/ jisakos-2018-000223).

${ }^{1}$ Orthopedic and Sports Medicine, Houston Methodist, Houston, Texas, USA ${ }^{2}$ Midwest Orthopedics at Rush, Rush University Medical Center, Chicago, Illinois, USA
\end{abstract}

\section{Correspondence to} Dr Joshua D Harris, Orthopedic and Sports Medicine, Houston Methodist, Houston, Texas, USA; joshuaharrismd@gmail.com

Accepted 21 April 2020 Published Online First 23 June 2020
Check for updates

(C) International Society of Arthroscopy, Knee Surgery and Orthopaedic Sports Medicine 2020. Re-use permitted under CC BY-NC. No commercial reuse. Published by BMJ.

To cite: Klavas DM, Duplantier N, Gerrie B, et al. J ISAKOS 2020:5:213-217.

\section{ABSTRACT}

Objectives To determine which outcome scores physicians are using in hip preservation surgery, as well as when they are administered, who administers them and on what platform.

Methods A cross-sectional survey was conducted to examine which patient-reported outcome (PRO) scores are being used by hip preservation surgeons, including hip joint-specific, lower extremity limb-specific, diseasespecific, general health, quality of life, pain, activity, spine and psychiatric wellness scores. Descriptive statistics were calculated. Heterogeneity was assessed using $l^{2}$ statistics.

Results Fifty-six surgeons responded (mean 169 arthroscopic, 65 open hip preservation surgeries per year; mean 13 years experience). 13\% of surgeons did not collect any patient outcome scores. A total of 25 different PROs were reported. Of 13 possible hip joint-specific outcome scores, the modified Harris Hip Score was most frequently collected (46\%), followed by International Hip Outcome Tool-12 (41\%) and Hip Outcome Score (38\%). There was considerable heterogeneity in hip jointspecific PROs (I $\left.1{ }^{2} 86 \%\right)$. The Short Form-12 was the most common general health score (30\%). Tegner and UCLA Activity scores were collected by $11 \%$ of participants. Fifty-nine per cent collected outcomes preoperatively, $45 \%$ at 3 months, $54 \%$ at 6 months, $61 \%$ at 1 year and $32 \%$ annually. Paper collection was the most common collection platform (46\%), and a dedicated research assistant was most frequently the source of data collection (34\%).

Conclusion This international survey demonstrates that although most hip preservation surgeons collect hip outcome scores, there is a large amount of heterogeneity in outcome scores used and method of collection. As hip preservation evidence continues to evolve, these results should emphasise the need for an initiative to standardise outcome score collection.

Level of evidence Level V.

\section{INTRODUCTION}

Patient-reported outcomes (PROs) are increasingly used in today's rapidly evolving healthcare environment. A value-based approach to healthcare provided by physicians emphasises high quality and low cost. Cost may be quantified using both direct and indirect methods. The quality of care is less easily quantified. Used by patients, physicians, hospitals and payers, PROs are among one of the few quantitative methods available to assess a patient's symptomatic state and response to interventions over time. Broadly defined,
What are the new findings?

- Patient-reported outcomes are collected by the majority of hip preservation surgeons.

- There is heterogeneity in outcome scores collected by hip preservation surgeons.

- There is heterogeneity in the methods by which outcome scores are collected.

- The most common collected scores are the modified Harris Hip Score, International Hip Outcome Toolhip outcome tool-12 and Hip Outcome Score.

outcome scores can be subjectively reported by patients or objectively reported by clinicians. ${ }^{1}$ Further categorised, these outcomes can be joint specific (eg, Hip Outcome Score), limb specific (eg, Lower Extremity Functional Scale), disease specific (eg, Arthritis Impact Measurement Scale), activity based (eg, Tegner), general health quality of life (eg, Short Form-12 (SF-12)) or pain based (eg, Visual Analogue Scale). Data received from PROs permit clinicians to internally (or externally) follow their patients' results, observe strengths and weaknesses, make adjustments and improve the overall quality of care they provide. Recent advancements in the ability to distribute and acquire patient outcomes with improved compliance make it easier to publicly report outcomes via peer-reviewed research and conference proceedings, resulting in translation of knowledge from study findings to clinical practice. In sub-specialised areas of orthopaedic surgery, such as hip preservation where the evidence base is constantly evolving, advances in outcome score collection is critical to ensure continual improvement in care provision.

Over the past five decades, multiple PRO approaches have been developed to continue to analyse both arthritic and non-arthritic conditions in and around the hip. ${ }^{1}$ There is currently much debate as to which PRO is 'best' for patients with non-arthritic hip diagnoses. ${ }^{2}$ Clinician-based surveys of practice patterns are frequently considered 'expert opinion' level V evidence. However, in specialties like hip preservation surgery with an evidence base that is rapidly evolving and no clear gold standards, these surveys provide a highly informative glimpse into the practice patterns of those clinicians who are leading and advancing the specialty. ${ }^{3}{ }^{4}$ The purpose of this investigation is to determine which scores physicians are using, as well as when they are administered, who administers them and on what platform. The authors 
hypothesise that this study will provide a snapshot of the disagreement among hip preservation surgeons that is already evident in the literature with regards to collecting, analysing and reporting hip outcome scores.

\section{METHODS}

Between June 2015 and August 2015, a seven-question, IRB (Institutional Review Board)-exempt, HIPAA (Health Insurance Portability and Accountability Act)-compliant, cross-sectional survey was conducted via email using SurveyMonkey (http://www. surveymonkey.com). The survey was emailed to hip surgeons identified via one of four methods: members of ISHA (International Society of Hip Arthroscopy), ANCHOR (Academic Network for Conservational Hip Outcome Research), MAHORN (Multicenter Arthroscopic Hip Outcomes Research Network) and a PubMed search of authors identified via a 'hip arthroscopy' algorithm. Invitations were sent to authors found within the first 200 citations not previously identified. Those identified surgeons without a contact email were excluded. There were 155 hip preservation surgeons contacted by email, 132 of whom practise in the USA and 23 of whom practise internationally. If a response was not documented within 2 weeks, subsequent email attempts were made, totalling four reminder emails. The survey was not endorsed by any regional, national or international medical, surgical or hip preservation society.

In all, the survey was composed of seven questions (online supplementary appendix). Three questions regarding the surgeon's arthroscopic and open hip preservation surgery volume and experience were posed. Questions regarding which hip outcome score questionnaires were collected from patients, as well as when they were collected, what platform was used to collect (paper hard copy or electronic) and who collected them were also posed. Likert-type questions were used where appropriate.

Results of each survey response were collected in a confidential manner and organised via the SurveyMonkey web tool. Each participant was instructed to complete every survey question. Survey participation and completion required that each participant answer every question. Descriptive statistics were calculated for each question. Continuous variable data were reported as mean \pm SD. Categorical data were reported as frequencies with percentages. Heterogeneity of outcome score utilisation was assessed using $\mathrm{I}^{2}(\mathrm{Q}-\mathrm{df}) /(\mathrm{Q}) \times 100 \%$, where $\mathrm{Q}$ is the $\chi^{2}$ statistic. An $\mathrm{I}^{2} 75 \%-100 \%$ represented considerable heterogeneity (50\%-90\% substantial heterogeneity; 30\%-60\% moderate heterogeneity; 0\%-40\% less important). Statistical significance was defined as a $\mathrm{p}$ value less than 0.05 .

\section{RESULTS}

In total, 56 responses (36\% response rate) were received from surgeons spanning six countries worldwide. Thirteen per cent of survey respondents practise outside of the USA. Table 1 summarises the demographics, surgeon volume, and surgeon experience in the field of arthroscopic or open hip preservation surgery. As a group, the survey respondents performed an average of $169 \pm 131$ (range 0-700) arthroscopic hip procedures per year, an average of $65 \pm 109$ (range 0-500) open hip procedures per year and possessed $13 \pm 9$ (range 1-35) years of experience in the field of hip preservation surgery. Of the 56 respondents, $6(11 \%)$ performed less than 50 arthroscopic cases per year while 36 (64\%) performed less than 50 open cases per year.
Table 1 Survey respondent demographics

\begin{tabular}{|c|c|}
\hline Surgeon experience (years), average $13 \pm 9$ & $\begin{array}{l}\text { Number of } \\
\text { respondents }\end{array}$ \\
\hline$<5$ & 13 \\
\hline $5-9$ & 14 \\
\hline $10-19$ & 14 \\
\hline $20-29$ & 11 \\
\hline$>30$ & 3 \\
\hline \multicolumn{2}{|l|}{ Operative volume (cases/year) } \\
\hline \multicolumn{2}{|l|}{ Arthroscopic, average $169 \pm 131$} \\
\hline $0-49$ & 6 \\
\hline $50-100$ & 11 \\
\hline 100-199 & 18 \\
\hline 200-299 & 9 \\
\hline 300-399 & 9 \\
\hline $400-499$ & 2 \\
\hline$>500$ & 1 \\
\hline \multicolumn{2}{|l|}{ Open, average $65 \pm 109$} \\
\hline $0-49$ & 36 \\
\hline $50-100$ & 4 \\
\hline 100-199 & 9 \\
\hline 200-299 & 3 \\
\hline 300-399 & 3 \\
\hline $400-499$ & 0 \\
\hline$>500$ & 1 \\
\hline \multicolumn{2}{|l|}{ Country of residence } \\
\hline USA & 49 \\
\hline Canada & 2 \\
\hline UK & 2 \\
\hline Switzerland & 1 \\
\hline Germany & 1 \\
\hline Australia & 1 \\
\hline
\end{tabular}

\section{Hip outcome scores}

Table 2 summarises the percentage of survey respondents who used each hip outcome score questionnaire. Forty-nine respondents $(87 \%)$ used at least one or more PROs. Forty-six respondents $(82 \%)$ used two or more PROs. The average number of outcome tools collected was 3.5 (range $0-10$ ). In all, 25 different outcome instruments were reported by those surveyed. The modified Harris Hip Score (mHHS) was the most commonly used questionnaire (46\%). The iHOT (International Hip Outcome Tool)-12 (41\%) was used more frequently than its longer version, the iHOT-33 (14\%). Considerable heterogeneity $\left(\mathrm{I}^{2} 85.6 \%\right)$ was present in the outcomes used. The SF-12 was the most frequently used general health quality-of-life questionnaire used (30\%). The Beck Depression Index (2\%) and Low Back Outcome Score (2\%) were reportedly used by only one surgeon. Both the Tegner Activity Score and UCLA Activity Score were collected by six surgeons (11\%).

\section{Outcome score collection protocols}

Fifty-nine per cent of surgeons collected outcome scores preoperatively (table 3). Postoperatively, surgeons most frequently collected scores at 6 months (54\%) and 1 year (61\%). Following 1 year after surgery, only $32 \%$ collected annual scores indefinitely. Most outcomes were collected on paper (46\%), versus electronic research databases (36\%), and electronic medical records (23\%). The source of data collection was most commonly a dedicated research assistant (34\%) (table 3). 


\begin{tabular}{|c|c|c|}
\hline Hip joint-specific outcome scores & $N(\max =56)$ & $\begin{array}{l}\% \\
\text { response }\end{array}$ \\
\hline Modified Harris Hip Score & 26 & 46.43 \\
\hline iHOT-12 (International Hip Outcome Tool) & 23 & 41.07 \\
\hline HOS (Hip Outcome Score) & 21 & 37.50 \\
\hline NAHS (Non-Arthritic Hip Score) & 10 & 17.86 \\
\hline Harris Hip Score & 9 & 16.07 \\
\hline iHOT-33 (International Hip Outcome Tool) & 8 & 14.29 \\
\hline $\begin{array}{l}\text { WOMAC (Western Ontario and McMaster } \\
\text { University) }\end{array}$ & 7 & 12.50 \\
\hline $\begin{array}{l}\text { HOOS (Hip Disability and Osteoarthritis } \\
\text { Outcome Score) }\end{array}$ & 7 & 12.50 \\
\hline Vail Hip Score & 5 & 8.93 \\
\hline Oxford Hip Score & 2 & 3.57 \\
\hline $\begin{array}{l}\text { HAGOS (Copenhagen Hip and Groin } \\
\text { Outcome Score) }\end{array}$ & 1 & 1.79 \\
\hline FJS-12 Hip (Forgotten Joint Score) & 1 & 1.79 \\
\hline AAOS Hip and Knee Outcome Score & 0 & 0.00 \\
\hline \multicolumn{3}{|l|}{$\begin{array}{l}\text { Lower extremity limb-specific outcome } \\
\text { scores }\end{array}$} \\
\hline $\begin{array}{l}\text { LE CAT (Lower Extremity Computerized } \\
\text { Adaptive Test) }\end{array}$ & 1 & 1.79 \\
\hline Lower extremity function scale & 0 & 0.00 \\
\hline Hamstring outcome score & 0 & 0.00 \\
\hline AAOS Hip and Knee Outcome Score & 0 & 0.00 \\
\hline \multicolumn{3}{|l|}{ Disease-specific outcome scores } \\
\hline $\begin{array}{l}\text { MACTAR (McMaster Toronto Arthritis Patient } \\
\text { Preference Disability Questionnaire) }\end{array}$ & 0 & 0.00 \\
\hline AIMS (Arthritis Impact Measurement Scale) & 0 & 0.00 \\
\hline \multicolumn{3}{|c|}{ General health, quality of life, pain and psychological outcome scores } \\
\hline Visual Analogue Scale & 24 & 42.86 \\
\hline Short Form 12 (SF-12)* & 17 & 30.36 \\
\hline Short Form 36 (SF-36)* & 10 & 17.86 \\
\hline EuroQol EQ5D-5L & 5 & 8.93 \\
\hline $\begin{array}{l}\text { VR-12 (Veterans Rand 12-Item General } \\
\text { Health Survey) }\end{array}$ & 2 & 3.57 \\
\hline Beck Depression Index & 1 & 1.79 \\
\hline EuroQol EQ5D-3L & 1 & 1.79 \\
\hline Zung Depression Index & 0 & 0.00 \\
\hline GROC (Global Rating of Change) & 0 & 0.00 \\
\hline $\begin{array}{l}\text { VR-33 (Veterans Rand 33-Item General } \\
\text { Health Survey) }\end{array}$ & 0 & 0.00 \\
\hline \multicolumn{3}{|l|}{ Activity scores } \\
\hline Tegner Activity Scale & 6 & 10.71 \\
\hline UCLA Activity Score & 6 & 10.71 \\
\hline Marx Activity Score & 2 & 3.57 \\
\hline HSAS (Hip Sports Activity Score) & 1 & 1.79 \\
\hline \multicolumn{3}{|l|}{ Spine Outcome Scores } \\
\hline Low back outcome score & 1 & 1.79 \\
\hline Oswestry Disability Index & 0 & 0.00 \\
\hline Do not collect hip outcome scores & 7 & 12.50 \\
\hline
\end{tabular}

\section{DISCUSSION}

This international survey investigation showed that of the 56 hip preservation surgeons who responded, 49 of them collected 25 different PRO tools. Although the mHHS was the most frequently used hip joint-specific PRO, it was used by less than half $(46 \%)$ of those surveyed. There was considerable
Table 3 Outcome score collection protocols

\begin{tabular}{|ccc}
\hline When do you collect your hip outcome scores? & N (max=56) & $\begin{array}{l}\% \\
\text { response }\end{array}$ \\
\hline Annually & 18 & 32.14 \\
\hline New patient visit & 26 & 46.43 \\
\hline Preoperatively & 33 & 58.93 \\
\hline 2 Weeks postoperatively & 9 & 16.07 \\
\hline 4 Weeks postoperatively & 0 & 0.00 \\
\hline 6 Weeks postoperatively & 11 & 19.64 \\
\hline 3 Months postoperatively & 25 & 44.64 \\
\hline 6 Months postoperatively & 30 & 53.57 \\
\hline 9 Months postoperatively & 3 & 5.36 \\
\hline 12 Months postoperatively & 34 & 60.71 \\
\hline Other & 10 & 17.86 \\
\hline How do you collect your hip outcome scores? & & \\
\hline Paper records & 26 & 46.43 \\
\hline Electronic medical records & 13 & 23.21 \\
\hline Electronic research database & 20 & 35.71 \\
\hline Other & 9 & 16.07 \\
\hline Who collects your hip outcome scores? & & \\
\hline Research assistant & 19 & 33.93 \\
\hline Patient gets automated reminders and completes & 17 & 30.36 \\
them on their own & & \\
\hline Nurse & 11 & 19.64 \\
\hline Doctor & 16 & 28.57 \\
\hline Fellow/resident/student & 6 & 10.71 \\
\hline Physician assistant & 10 & 17.86 \\
\hline Other & 14 & 25.00 \\
\hline
\end{tabular}

heterogeneity in the outcome scores used (12 out of 13 available hip joint-specific questionnaires used by at least one surgeon). Fifty-nine per cent collected preoperative outcome scores and $54 \%$ and $61 \%$ collected postoperative outcomes at 6 and 12 months, respectively. Thirty-two per cent of surgeons collected long-term annual outcome scores postoperatively. Most outcome scores were collected on paper (46\%) by a dedicated research assistant (34\%). Such heterogeneity is reflective of the current state of hip outcome score reporting.

Universal standardisation of hip outcome score collection can allow for more consistent cross-study comparisons to be made. ${ }^{5}$ The ability to draw conclusions from large datasets in the literature can help predict who may perform poorly or which patients will be subject to postoperative complications. ${ }^{6}$ Several challenges exist in the widespread adoption of universal outcome score collection by hip preservation surgeons (table 4). To meet these challenges, several PRO tools have been developed and validated. Femoroacetabular impingement (FAI) is a relatively modern diagnosis that could see strong improvements in its surgical management via hip arthroscopy, if FAI patient outcomes are consistently measured.

Multiple systematic reviews have been performed to identify the most useful PRO for gathering data related to hip arthroscopy patients. Ramisetty et al used the taxonomy described by Mokkink et al (reliability, validity and responsiveness) to critically appraise a current list of PRO measure ${ }^{17}$ and recommended the iHOT-33 be the standardised PRO tool for the future of hip surgery. Kemp et al similarly suggested the iHOT-33 plus Hip Disability and Osteoarthritis Outcome Score (HOOS) be used universally. ${ }^{13}$ In the current study, the iHOT-33 ranked as only the sixth most popular Hip Joint Specific Outcome Score, while the HOOS ranked as tied for the seventh most popular Hip 


\begin{tabular}{lll}
\hline Table 4 & Challenges to outcome score collection in hip preservation surgery & \\
\hline Issue & Challenge & What is needed? \\
\hline $\begin{array}{l}\text { Which scores should be } \\
\text { collected? }\end{array}$ & $\begin{array}{l}\text { No perfect score exists_-over one dozen are frequently used in arthritic and } \\
\text { non-arthritic conditions }\end{array}$ & $\begin{array}{l}\text { Scores with optimal psychometric properties-development, } \\
\text { reliability, responsiveness, validity }\end{array}$ \\
$\begin{array}{l}\text { When should scores be } \\
\text { collected? }\end{array}$ & $\begin{array}{l}\text { Must be frequent enough to properly monitor but not be overly burdensome } \\
\text { to patient, induce fatigue and decrease compliance }\end{array}$ & $\begin{array}{l}\text { Non-redundant, convenient and quick questionnaires so that may } \\
\text { be given enough pre-intervention and post-intervention to increase } \\
\text { amount of data but not so frequent that compliance drops }\end{array}$ \\
$\begin{array}{ll}\text { Who is responsible for } \\
\text { collecting scores? }\end{array}$ & $\begin{array}{l}\text { For patient-reported outcomes, clinician involvement introduces bias, takes } \\
\text { a significant amount of time to collect, may require other staff to collect }\end{array}$ & $\begin{array}{l}\text { Automated reminders that may be completed at patient's } \\
\text { convenience so office involvement is minimal }\end{array}$ \\
$\begin{array}{l}\text { What is the best platform for } \\
\text { collecting scores? }\end{array}$ & $\begin{array}{l}\text { Storage and analysis of paper forms are logistically suboptimal. Electronic } \\
\text { platforms may be costly, inaccessible to select patient populations }\end{array}$ & $\begin{array}{l}\text { Inexpensive, secure, user-friendly, universally accessible electronic } \\
\text { databases integrated in the medical record }\end{array}$ \\
\hline
\end{tabular}

Joint Specific Outcome Score used. A 2018 systematic review by Stone et al found 21 different PRO tools used in the hip arthroscopy literature with an average of 3.2 PROs per article. ${ }^{6}$ This is a similar finding to the results of this survey which found 25 outcome tools used, with an average of 3.5 PROs per surgeon. The same systematic review concluded that based on responsiveness and psychometric properties, the iHOT tools should be employed as a widespread outcome score. ${ }^{6}$

The iHOT-33 was developed in 2012 by members of the MAHORN and has shown excellent reliability, validity and responsiveness. ${ }^{13}$ While the iHOT-33 has been useful in research settings, the number of questions can be burdensome in routine clinical settings. ${ }^{8}$ As a result, the iHOT-12 was established by Griffin et al on behalf of MAHORN. ${ }^{8}$ The results from the current study reflect the ease of use of the iHOT-12 as compared with iHOT-33. The authors of this paper support that the iHOT-12 should be universally used to evaluate patients both preoperatively and postoperatively.

The HOOS, HAGOS and HOS outcome tools are relatively cumbersome questionnaires (40, 37 and 28 questions, respectively) that are viewed as reliable and valid. ${ }^{1}$ Only the HOS had significant utilisation by hip surgeons who responded in this study. One possible explanation for the shortcomings of the HOOS and HAGOS in the subset of hip preservation surgery is their questions were initially designed with an older, more sedentary population in mind, ${ }^{1}$ perhaps lending their utility as joint arthroplasty PROs but not as hip preservation surgery PROs.

The HOS, whose validation was conducted on patients with FAI and labral pathology, consists of two subscales including activities of daily living (HOS-ADL, 19 questions) and sports (HOS-SSS, 9 questions). ${ }^{1}$ Despite its lack of focus on patient's symptoms, it was the third most common hip joint-specific questionnaire used by the cohort of survey respondents. The mHHS, which primarily measures pain and function, was originally designated for an elderly population who may be less likely to undergo hip preservation surgery, thus explaining why the mHHS is not yet validated for hip arthroscopy and joint preservation. ${ }^{12}$ Nonetheless, the mHHS was widely represented among this survey's respondents and was also the most commonly reported PRO in the 2018 review by Stone et al. ${ }^{6}$ One hypothesis for this popularity is the presence of a pain component in the questionnaire. ${ }^{5}$

General outcome measures are often viewed as secondary tools when compared with the disease-specific measures for FAI. ${ }^{2}$ However, the results from the current study disagree with this trend, demonstrating that the SF-36, SF-12 and EuroQol-5D are all less commonly used as compared with the more rudimentary visual analogue pain scale (VAS). In a 2017 study on FAI outcomes, Chandrasekaran et al showed that the VAS can model patient satisfaction trends in four commonly used PROs (mHHS,
HOS-ADL, HOS-SSS, NAHS) with moderate correlation. ${ }^{9}$ In addition, the SF-36, SF-12 and EuroQol-5D require purchase through a license application and registration form, which may disincentivise their use. ${ }^{3}$ On the contrary, the Veterans Rand 12-item general health form (VR-12) and Veterans Rand 33-item general health form (VR-33) are available free of charge and hold the same validation as both SF tools. ${ }^{10}$

Activity-level measurements can provide useful information not represented in the disease-specific outcome measures. ${ }^{2}$ The UCLA activity score is the most frequently used activity scoring system in studies of FAI. ${ }^{11}$ The Tegner Activity Scale was developed to assess patients with an anterior cruciate ligament injury, ${ }^{12}$ but unlike the UCLA score, the Tegner Scale provides work components stratified by physical demand and sportspecific activities. Currently, no specific measure is specifically recommended to assess the activity level of patients with FAI, ${ }^{3}$ but tools such as the hip sports activity scale (HSAS) were developed to assess hip outcomes in sports-active FAI. ${ }^{13}$ In the current study, $10 \%$ of surgeons used the UCLA score, $10 \%$ of surgeons used the Tegner Scale and only one surgeon used the HSAS tool.

Currently, there are no validated recommendations regarding the timing to implement PRO scores. Preoperative data can be compared with postoperative PROs with regard to function and symptoms. However, it is unknown when it is most beneficial to gather data postoperatively. Too many or too frequent questionnaires could burden the patient and cause inappropriate reporting. Only 17 surgeons in the current study collect follow-up annually, likely representing the group of hip preservation surgeons who routinely publish data. The authors hypothesise that if not for the purpose of publishing research data, the other motivating factors to collecting PROs are either to comply with quality control demands or because PROs are becoming recognised as a measure of quality by insurance payers. ${ }^{14}$

The method of data collection reported by survey respondents was most commonly on hard pages collected by research assistants. Davis et al reported in 2011 that more than $10 \%$ of the 83 000 physician assistants (PAs) in medical practice were working in orthopaedic surgery. ${ }^{15}$ The current study reported that $18 \%$ of the respondents used a PA for data collection while $29 \%$ of the physicians collected the data personally. Conversely, 34\% of the survey respondents used a dedicated research assistant for data collection. Clinical efficiency is at risk whenever a PA or physician is required to collect data. A research assistant may be the most appropriate data-gathering representative in this situation. Less than a quarter of the survey respondents used electronic medical records (EMRs) as an aid to collect PRO data, while over one-third of respondents implemented an electronic research database (ERD), despite a recent trend towards quality measures promoting EMR. Third-party software systems such as OBERD (Outcomes Based Electronic Research Database, 
Columbia, MO) and PROMIS (Patient Reported Outcome Measurement Information System, United States Department of Health and Human Services) can now be integrated into a clinical infrastructure to help streamline data collection.

The main strength of this study is its ability to gather an aggregate of clinical practice data from a cohort of international surgeons practising hip preservation surgery (mean 169 arthroscopic surgeries/year). The limitations of this study are inherent to any survey, including the possibility of selection bias and response bias. The survey was not pre-screened by a panel of experts for validity nor reliability; however, the quality of this survey and its findings can be assessed by a validated tool such as the NIH's Quality Assessment Tool for Observational Cohort and Cross-Sectional Studies. ${ }^{16}$ The route of survey recruitment through email may pose bias as potential participants may lack this method of communication. An overall response rate of only $36 \%$ excludes data of almost two-thirds of intended participants from being analysed, thus limiting the external validity of these study findings. Responsiveness to future international surveys may be improved if study co-ordinators and/or department secretaries are contacted in addition to the surgeons. Finally, inherent to this study is the lack of contribution from countries other than the USA, specifically Mexico, Japan, South America, Greece and Chile. The paucity of responses from these locations could be attributed to language barriers since the survey was delivered in an English-only format. The degree to which language influenced is unknown, but the authors believe it may have played a role.

\section{CONCLUSION}

An international cohort of hip preservation surgeons reported a wide variety of methods for collecting hip outcome scores using an internet-based survey. As hip preservation surgery evidence continues to evolve, these results should emphasise the need for an international initiative for standardisation of outcome score collection.

Twitter Joshua D Harris @JoshuaHarrisMD

Contributors All authors participated meaningfully and intellectually to this report, and every effort was made to keep the writing concise and compliant with journal specifications.

Funding The authors have not declared a specific grant for this research from any funding agency in the public, commercial or not-for-profit sectors.

Competing interests PCM—Arthrex, Inc.: research support; DePuy, A Johnson \& Johnson Company: research support; Journal of Knee Surgery: editorial or governing board; Orthobullets.com: editorial or governing board; Vericel: paid presenter or speaker. SJN-Allosource: research support; American Journal of Orthopedics: editorial or governing board; American Orthopaedic Society for Sports Medicine: board or committee member; Arthrex, Inc: research support; Arthroscopy Association of North America: board or committee member; Athletico: research support; DJ Orthopaedics: research support; Linvatec: research support; Miomed: research support; Ossur: IP royalties; paid consultant; Smith \& Nephew: research support; Springer: publishing royalties, financial or material support; Stryker: paid consultant; research support. KEV — In2Bone: IP royalties; paid consultant; stock or stock options; Solana: IP royalties; paid consultant; Wright Medical Technology, Inc.: stock or stock options. JDH—AAOS: board or committee member; American Orthopaedic Society for Sports Medicine: board or committee member; Arthroscopy: editorial or governing board; Arthroscopy Association of North America: board or committee member; DePuy, A Johnson \& Johnson Company: research support; Frontiers in
Surgery: editorial or governing board; NIA Magellan: paid consultant; Ossur: paid consultant; paid presenter or speaker; SLACK Incorporated: publishing royalties, financial or material support; Smith \& Nephew: paid consultant; paid presenter or speaker; research support.

Patient consent for publication Not required.

Ethics approval All procedures followed were in accordance with the ethical standards of the responsible committee on human experimentation and with the Declaration of Helsinki. Local Institutional Review Board (IRB) exemption status was obtained.

Provenance and peer review Not commissioned; externally peer reviewed.

Data availability statement Data are available on reasonable request. All data relevant to the study are included in the article or uploaded as online supplementary information.

Open access This is an open access article distributed in accordance with the Creative Commons Attribution Non Commercial (CC BY-NC 4.0) license, which permits others to distribute, remix, adapt, build upon this work non-commercially, and license their derivative works on different terms, provided the original work is properly cited, an indication of whether changes were made, and the use is noncommercial. See: http://creativecommons.org/licenses/by-nc/4.0/.

\section{ORCID iD}

Joshua D Harris http://orcid.org/0000-0002-7606-2473

\section{REFERENCES}

1 Ramisetty N, Kwon Y, Mohtadi N. Patient-reported outcome measures for hip preservation surgery — a systematic review of the literature. J Hip Preserv Surg 2015;2:15-27

2 Harris-Hayes M, McDonough CM, Leunig M, et al. Clinical outcomes assessment in clinical trials to assess treatment of femoroacetabular impingement: use of patientreported outcome measures. J Am Acad Orthop Surg 2013;21:S39-46.

3 Kemp JL, Collins NJ, Roos EM, et al. Psychometric properties of patient-reported outcome measures for hip arthroscopic surgery. Am J Sports Med 2013:41:2065-73.

4 Thorborg K, Hölmich P. Measurement qualities of hip and groin outcome scores: letter to the editor. Am J Sports Med 2014;42:NP7-13.

$5 \operatorname{Sim}$ Y, Horner NS, de Sa D, et al. Reporting of non-hip score outcomes following femoroacetabular impingement surgery: a systematic review. J Hip Preserv Surg 2015:2:224-41.

6 Stone AV, Jacobs CA, Luo TD, et al. High degree of variability in reporting of clinical and patient-reported outcomes after hip arthroscopy. Am J Sports Med 2018;46:3040-6.

7 Mokkink LB, Terwee CB, Patrick DL, et al. The COSMIN study reached international consensus on taxonomy, terminology, and definitions of measurement properties for health-related patient-reported outcomes. J Clin Epidemio/ 2010;63:737-45.

8 Griffin DR, Parsons N, Mohtadi NGH, et al. A short version of the International Hip Outcome Tool (iHOT-12) for use in routine clinical practice. Arthroscopy 2012;28:611-8.

9 Chandrasekaran S, Gui C, Walsh JP, et al. Correlation between changes in visual analog scale and patient-reported outcome scores and patient satisfaction after hip arthroscopic surgery. Orthop J Sports Med 2017;5:232596711772477.

10 Kazis LE, Miller DR, Skinner KM, et al. Applications of methodologies of the Veterans Health Study in the VA healthcare system: conclusions and summary. J Ambul Care Manage 2006;29:182-8.

11 Amstutz HC, Thomas BJ, Jinnah R, et al. Treatment of primary osteoarthritis of the hip. A comparison of total joint and surface replacement arthroplasty. J Bone Joint Surg Am 1984:66:228-41.

12 Tegner Y, Lysholm J. Rating systems in the evaluation of knee ligament injuries. Clin Orthop Relat Res 1985;198:42???49-9.

13 Naal FD, Miozzari HH, Kelly BT, et al. The Hip Sports Activity Scale (HSAS) for patients with femoroacetabular impingement. Hip Int 2013;23:204-11.

14 Chenok K, Teleki S, SooHoo NF, et al. Collecting patient-reported outcomes: lessons from the California Joint Replacement Registry. EGEMS 2015;3:1196.

15 Davis A, Marriott T. Orthopaedic surgeons and PAs: best practices. AAOS Now, 2011Dec. Available: https://www.aaos.org/aaosnow/2011/dec/managing/managing2/ [Accessed 3 Feb 2020].

16 Study Quality Assessment Tools. US Department of Health and Human Services. Available: https://www.nhlbi.nih.gov/health-topics/study-quality-assessment-tools [Accessed 3 Feb 2020]. 